\title{
CORRESPONDENCE
}

\section{Irish evidence}

SIR - Mr Peter H. Roberts's letter (Nature 19

March, p.184) offers the importation of infected Irish cattle as an explanation for the fluctuating incidence of bovine tuberculosis in the South West region between 1974 and 1980. It also says that the Zuckerman report carefully avoids this factor. I should like to set out the facts.

Table 10, on page 57 of the report, records the ministry's assessment of the sources of bovine tuberculosis infection in all infected cattle herds in Great Britain during 1972-1978, including imported Irish cattle. The figures for the South West and Sussex show 331 cases attributed to badgers and 4 (of which 2 were in Sussex) to imported Irish cattle. The totals for the rest of Great Britain are 0 and 171 respectively. It is little wonder therefore that Lord Zuckerman did not pursue the Irish cattle question when investigating infection in badgers in the South West.

The following breakdown of the figures for infection attributed to Irish cattle imports further detracts from the force of $\mathrm{Mr}$ Roberts's argument

$\begin{array}{ccc} & \text { Great Brituin } & \text { SW England } \\ 1972 & 59 & 1 \\ 1973 & 23 & 0 \\ 1974 & 22 & 0 \\ 1975 & 23 & 0 \\ 1976 & 23 & 1 \\ 1977 & 12 & 0 \\ 1978 & 13 & 0 \\ \text { TOTAL } & 175 & \overline{2}\end{array}$

Traditionally the Irish trade has been, and still is, mainly with the North-East of England and East Scotland. In the 2-year period before 1976 when, $\mathrm{Mr}$ Roberts suggests, cattle infected with bovine tuberculosis were imported from the Irish Republic, there was no increase in disease incidence from this source. What the figures do show is the effectiveness of the decision to introduce, in 1976, pre-export testing of Irish cattle.

\section{W. H. G. REES}

Ministry of Agriculture, Fisheries and Food, Tolworth, Surrey, UK

\section{Who is Nabi?}

SIR - Readers may wish to know that the name of Isadore Nabi, the signatory of a recent letter criticizing my views on sociobiology and ethics (Nature 19 March, p.183) is fictitious. Should the writer ever make a statement over his own name, I hope he will confess that he lifted the two 1975 phrases of mine out of context in a way that reverses the meaning of one and makes it appear to contradict the other. I also trust that he will mention my later and fuller treatments of sociobiology and ethics in On Human Nature (1978) and The Tanner Lectures on Human Values, Volume I (1980).

EDWARD O. WILSON

Museum of Comparative Zoology,

Harvard University, Massachusetts, USA

Isadore Nabi is believed to be the pseudonym of Professor R.C. Lewontin of Harvard University - Editor, Nature.

\section{Erratum}

An incorrect spelling was given for the oak wilt fungus in the 26 March issue (Nature 290, p.284). The organism is Ceratocystis fagacearum and the beetle involved in its transfer is Scolytus.

\section{Darwin's truths}

SIR - The letter from your correspondents at the British Museum (Natural History) (Nature 12 March, p.82) relating to your editorial "Darwin's death at South Kensington" (26 February, p.735) fully supports your contention that something is amiss at that institution. The writers do not appear to understand the difference between a theory and a fact. When Darwin's Origin of Species was published in 1859 , it was presented as a theory. It was then, and for long afterwards, proper to refer to it as "the theory of evolution'. But since then the evidence for the theory has accumulated from many different sources and in many ways, among them natural and laboratory experiments. Wherever and by whatever means the theory has been tested, it has withstood every attempt at falsification.

The atom at the beginning of this century was a theory. No one today will doubt that it is a fact. Yet no one has ever seen an atom. Yet we have seen evolution in process before our very eyes in heritable changes in many forms, perhaps the most remarkable and obvious is the well-known case of industrial melanism in moths. What kind of proof do the South Kensington writers require before they will be willing to accept evolution as a fact? There are many differing theories concerning the mechanisms of evolution, and these are all to the good, but the fact of evolution as a process of change, surely, cannot be denied. The proofs for it are overwhelmingly clear.

Department of Anthropology, Ashley Montagu

Princeton University,

New Jersey, USA

SIR - I am at a loss to understand what all the fuss is about concerning the phrase "if the theory of evolution is true"'. Darwin used it. I quote from Origin of Species:

"There is another and allied difficulty which is much more serious. I allude to the manner in which species belonging to several of the main divisions of the animal kingdom suddenly appear in the lowest fossiliferous rocks ... If the theory of evolution be true it is indisputable that before the lowest Cambrian strata was deposited long periods elapsed as long or probably far longer then the whole interval from the Cambrian to the present day, and that during these periods the world swarmed with living creatures ... The difficulty of assigning any good reason for the absence of vast piles of strata rich in fossils beneath the Cambrian system is very great."

This, coupled with the following quote by Dr W.R. Thompson, Fellow of the Royal Society, in the foreword of the Origin of Species (1956) does nothing to inspire confidence or belief in the current theories of how life started or progressed on Earth.

"It does appear to me in the first place that Darwin in the Origin of Species was not able to produce palaeontological evidence sufficient to prove his views, but that the evidence he did produce was adverse to them, and I may note that the position today is not notably different . . As we know there is a great divergence of opinion among biologists not only about the causes of evolution but even about the actual process, the divergence exists because the evidence is unsatisfactory and does not permit any certain conclusions." I am left wondering which theory requires the most blind faith.

Liverpool, $U K$

Gordon SMITH

\section{Room for all}

SIR - At first amused, I am now saddened by the "Death of Darwin" controversy (Nature, 26 February, p.735 et seq.). We have slipped back a hundred years: how long before letters signed Wilberforce and Huxley appear? Why "either-or"'? Why cut off either right or left hands? Is there not room for Darwin, Hennig, God - and even Marx?

Cambridge, UK

J.R. BAKER

\section{Popper's philosophy}

\section{SIR - Accusations that museum displays} organized in the light of cladistic philosophy represent creeping Marxist-Leninism were bad enough. But when Nature sees fit to defend the scientific status of Darwinism on the grounds that "metaphysical theories are not necessarily bad theories" "then matters philosophical have truly gotten out of hand.

It should come as no surprise to those familiar with the writings of various cladists that the writings of Professor Popper on evolutionary theory are held in great esteem. After all, he has argued for years that no view of history, whether human, biological or technological, admits of the classification scientific. For Popper the events of history are unique and, thus, not amenable to systematic explanation via theories of any sort ${ }^{2}$. Since cladists find the infusion of the least amount of theoretical insight into classification suspect in much the same way that their positivistically minded cousins, the phoneticists, did a decade or so ago, it is hardly surprising that they would greet the rediscovery of Professor Popper's writings from the 1940 s and 1950 s with great glee.

Popper's hostility to evolutionary theory explains the favour his views receive from systematists fond of cladism. But it does not explain why this same hostility should inform the judgments others make of the scientific status of Darwinism. Popper's views have been roundly and soundly criticized by numerous philosophers interested in the scientific status of evolutionary theory. The apparently timeless contentions that the theory is (1) tautologous, (2) unfalsifiable, (3) lacks predictive power and (4) lacks confirmation have shown to be false by a decade of scholarship in the philosophy of biology dating from the appearance of David Hull's Philosophy of Biological Science ${ }^{3,4}$. Why Nature should choose the cladists' favourite philosophical authority over the ruminations of contemporary authors gives one pause not about politics but about the reading habits of the scientific community.

There are numerous reasons for not taking Professor Popper's criterion of demarcation of science and non-science seriously. Perhaps the most obvious is that it just does not cut well - cosmology and evolutionary theory wind up in the metaphysical hopper, astrology 
and phrenology make the grade as science false science but neverthess science.

Numerous other contributors to the philosophy of science such as Nagel, Hempel, Hanson, Toulmin, Kuhn, Shapere, Lakatos, McMullin and many others have shown serious conceptual flaws in Popper's defence of the falsifiability criterion for demarcating science from non-science ${ }^{5}$

Since the issue is so badly mauled in the Nature editorial let us take un the matter of the falsifiability of Darwinism since it seems of such great concern to cladists, creationists, and correspondents to this journal. The issue if stated as the question, "Is Darwinism falsifiable?" admits of a simple answer - yes.

If we are talking about the version of evolutionary theory propounded by Darwin in the Origin, then that theory has been shown false many times over. It claimed that all organic variation could be accounted for by natural selection and a tendency to inherit among all creatures. This is false. Mutation and recombination at the level of genes refute the adequacy of Darwin's posited mechanisms. Darwin claimed that the bulk of speciation occurred through anagenesis evolution within a lineage. This is false.

Cladogenesis or the splitting of an interbreeding population into two groups via natural barriers or other means accounts for the bulk of speciation. Darwin claimed that social behaviour exists in insects as a consequence of group benefit. This is false. Social behaviour exists among many insects as a consequence of kin selection, reciprocal altruism, parental manipulation or some combination of these mechanisms. This list could go on. The point is that evolutionary theory, like all theories in science is constantly tested, refined, modified, adapted and rewritten. The issue confronting defenders of the validity and utility of evolutionary theory in its early or modern forms is not whether it is science or not - Darwin himself certainly settled that matter with admirable skill in the empirical and analogical evidence he brought forward in his own writings. Rather the question is how does one go about invalidating scientific theories that constantly change and evolve - an issue that ought to attract the attention of the cladists if not the creationists.

How true is the theory of evolution? It is as true a theory as there is in science. Which is to say it depends on who is asking and when. Of course the theory of evolution is not a fact. Evolution is a fact and the theory of evolution tries to explain this fact. But the theory of evolution surely passes muster as science, even on the out-dated grounds cited by Professor Popper in his early work. (Even he no longer believes in the adequacy of his early analyses of evolutionary theory ${ }^{7}$.) The real question that should concern scientists is whether they know enough about current thinking in the history and philosophy of science to know a sound theory when it stares them in the face a circumstance unlikely to occur at the British Museum unless this ignorance is alleviated.

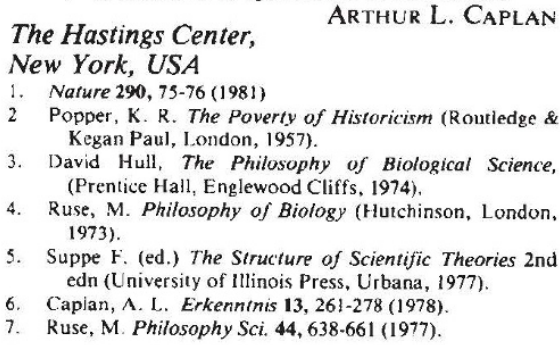

\section{Academia stagnant?}

SIR - I see no reason for your concern

(Nature 19 March, p.175) about the ability of British universities to recruit young scientists to academic posts. The present policy of recruiting young persons in their mid-twenties and sometimes without postdoctoral or international experience has so little merit that nothing would be lost if this recruitment of lecturers was totally ended. The best of our young scientists will wish to stay longer in full-time research and will continue to be available to the universities for years to come.

The rapid recruitment of academic staff in the 1960s expansion phase is unlikely to be the cause of stagnation in science departments. Where stagnation exists it is fairly certain that the department has defective leadership which might very well result from easy promotions gained in the years of expansion. Universities should, especially when resources are tight, recruit scientists into permanent teaching posts later in their careers than has been customary in Britain. A changed policy could provide continuing opportunities for the present generation of young scientists. Retirements and early retirements will improve some departments and at the same time allow new entrants or well justified internal promotions which ought to maintain the intellectual vitality of any department worth keeping.

School of Biological Sciences, J.R. PEnswick University of East Anglia, Norwich, UK

\section{Freedom from NATO}

SIR - With the mounting concern in your columns on measures which scientists should take to ensure academic freedom for colleagues deprived of their rights, it is surprising that you publicize the NATO Advanced Study Institutes, that scientists are happy to perform on the stage which NATO sets, and that no mention of this paradox has been made in your correspondence.

No doubt these conferences fulfil a useful scientific function in promoting exchange of information in very congenial surroundings. Under normal circumstances, the argument that funds (from a rather dubious source) were being channelled to a good cause would have been sufficient to rationalize the situation. In some cases there is also the hope that the opinions of the scientific community will filter back along this channel, and that contact with sensitive institutions will lead to a more extensive dialogue and to a greater opportunity for diplomatic manoeuvres. Often, such occasions bring us into contact with scientists who have difficulty in meeting foreign workers because of governmental restrictions.

These conditions do not apply to attendance at NATO-supported conferences. There is little evidence that the meetings provide a forum for discussion with NATO officials in any way which would allow scientists to exercise their social responsibility. Nor could it be claimed that the activities of the conferences could not easily take place under other auspices. But most seriously, at a time when nuclear installations in Europe, products of scientific ingenuity, threaten the peace of our own and other countries, this close relationship between scientists and NATO can only be seen from outside as complete approval for (if not connivance with) the increasingly military orientation of our society.
This association with NATO must also affect the scientists themselves. After participation in any symposium it is difficult to leave without feeling some debt of gratitude to the organizers who lavish money and attention on their charges. Qualms about the ethics of the institution running it are henceforth stiffled. Thus the NATO scientific conference is a highly effective public relations exercise both for the participants, and those who look to scientists for a lead in problems created by technology. How can Soviet colleagues be expected to take our views seriously when they see the strength of our opinions so cunningly controlled by political agencies? If our protests are to carry conviction in any field, we should dissociate ourselves from the influence of organizations like NATO, and take every opportunity to make this known publicly. ROGER R.C. NEW University of Liverpool, $U K$

\section{Conservation sites}

SIR - Many criticisms can be levelled at the system of Sites of Special Scientific Interest (SSSIs) but Muir's arguments (Nature 12 March p.82) are untenable.

Extinction may be "normal" but that is irrelevant to "value", To analogize, we will all die, but do not usually accept this as an excuse for murder. We are replacing complex ecosystems with much simpler landscapes, allowing for fewer species to exist or appear.

In a limited sense, rarity may support a value judgement of "biological deficiency", and the mere presence of a rarity may be poor grounds for conservation; but rare species can be good indicators of environmental quality when considered along with other evidence.

SSSI status may result in a "loss of freedom" of the owner. Losing such sites is a far greater "loss of freedom": it destroys our options and those of future generations, for we cannot replace them.

It is also misleading to allege just that protection of SSSIs is a cost to their owners: it prevents owners increasing their income by reclaiming the site, but that increase would itself be a cost to the taxpayer in terms of grants for reclamation, and later subsidies.

It is astonishing that someone from a university zoology department could contend that "Once . . . information is recorded and published ... nothing new will be learned by preservation"'. No complete record of any site or habitat exists, and the same material can generate an infinite variety of "descriptions". Frequently we cannot turn to the literature for basic data to test new theories - we have to test them through fresh fieldwork designed specifically for that purpose. If we lose the field sites, ecology becomes metaphysics and not science, and to rely just on the environments we are creating today leaves us a severely restricted data base.

This necessity has fortunately been recognized in other fields. Once, excavators of bone caves destroyed vast storehouses of information by removing every vestige of material but failing to distinguish stratified deposits. Later workers recognized strata but again lost vital information by failing to extract pollen, rodent bones, and other small items. Now sections of deposit are left undisturbed for the future application of new ideas and techniques. Ecologists need similar opportunities. Hoddesdon, Herts., UK
KEvin A. Roberts 